GLOBAL JOURNAL OF SOCIAL SCIENCES VOL 18, 2019: 23-32

COPYRIGHT@ BACHUDO SCIENCE CO. LTD PRINTED IN NIGERIA. ISSN 1596-6216

www.globaljournalseries.com; Info@globaljournalseries.com

\title{
SENSE PERCEPTION AND THE PROBLEM OF ILLUSION
}

\section{ODOZOR, UCHE S. AND OKONKWO, STANISLAUS O.}

(Received 13 December 2018; Revision Accepted 9 February 2019)

\begin{abstract}
This paper is a study of the problem of illusion in sense perception, using the methods of critical exposition and content analysis as tools of engagement. For decades, post-modern epistemology was steeped in the murky waters of the brilliant, skeptic argument from illusion, according to which the senses could not be relied upon for knowledge of the external world of reality, due to problems believed to be inherent in sensory perception. Why was the argument from illusion so important to epistemologists as to elicit enormous interest for such a long time? What are the implications of the argument for science? Did the argument from illusion portend any real danger for the foundations of empirical knowledge claims, as supposed by many frontline epistemologists? Exploring the concept and science of perceptual illusion, and the implications of the argument from illusion for science and epistemology, the paper found that the argument failed as a refutation of direct realism because it views illusion as the norm rather than an exception, and portrays human knowing process as an automatic, rather than a procedural, gradual phenomenon.
\end{abstract}

KEYWORDS: argument from illusion, empiricism, epistemology, science, skepticism

\section{INTRODUCTION}

This paper is a critical exposition and examination of the problem of illusion in sense experience, or sensory perception. In epistemology, this problem is traditionally posed as challenge to commonsense realism, the belief that objects of experience are directly or immediately accessible to the senses in perception. This belief formed the basis of the submission of 17 th century empiricism that the senses, prior to and independent of reason, are the valid means of acquiring knowledge and truth about objective reality (Hamlyn, 1967). Contrary to this assumption, it is argued that: "if illusions and hallucinations are possible, then perception, as we ordinarily understand it, is impossible" (Crane and French, 2016:6). The possibility of illusion and hallucination in human perceptual experience apparently makes it doubtful that the senses convey to the intellect what the outside world actually presents to them. This paper subjected the sceptical position to a critical analysis and found that it is invalidated by two factors: the first is that illusions are not the norm, but only the exception, in human perception; and the second is that human knowledge is a gradual and procedural phenomenon, rather than an instant, magical attainment of perfect comprehension of reality.

\section{CONTINENTAL RATIONALISM VS. BRITISH EMPIRICISM}

Rationalism, in the 17th century context, is the philosophical system according to which reason is the primary means by which the human mind

Odozor, Uche S., Department of Communication and General Studies, University of Agriculture, Abeokuta, Abeokuta, Nigeria

Okonkwo, Stanislaus O., Department of Philosophy, University of Ibadan, Ibadan, Nigeria

(C) 2019 Bachudo Science Co. Ltd. This work is licensed under Creative Commons Attribution 4.0 International license. 
attains knowledge of reality, prior to, and independent of, sense experience (Hamlyn, 1967). To buttress this position, the theory that ideas are "innate" to the human mind or intellect was advanced (Stroll and Martinich, 2017). In Theaetetus, Plato claimed that sense experience has a fleeting character, as the things apprehended by it are subject to change. As a result, it cannot be the source of knowledge; rather, knowledge is recollection of insights already accumulated in the intellect in previous existence. Plato's views were rejected by Aristotle, in favour of the notion of tabula rasa ('unscribed tablet'), which views the intellect as being originally a clean slate, until different aspects of human experience are gradually registered on it (De Anima, iii, 4). Thomas Aquinas, in Medieval European philosophy, substantively followed Aristotle on this notion (Summa Theologiae I, q.84; art.3).

Seventeenth century Rationalism was championed by Rene Descartes, who sought a system in which the scientific explanation of nature would be in agreement with a solidly built philosophy. Arguing from the conscious "self," Descartes proceeded to the reconstruction of all that can be known. Only "clear and distinct" ideas which are innate (prior to experience) find in their internal evidence the sign of their value (Descartes, 1997:176ff.; Raeymaker, 1962:20). Descartes recognised two kinds of substances: thought, which is the substance of the conscious self; and extension, which, with its modes of figure and movement, constitutes the reality of the material world. Baruch de Spinoza carried out a systematic arrangement of principles and axioms, with the aim of explaining reality the way geometry explains the relations and movements between different aspects of the material world. If every definition or clear and distinct idea is true, then it follows that a complete and systematic arrangement of true ideas will give us a true picture of reality, for "the order and connection of ideas is the same as the order and connection of things" (cited in Stumpf, 1994:249). Gottfried Leibniz distinguished between the ideas of perception and those of reason, or the understanding; between the truth of reason (necessary truth) and truth of fact (contingent truth). According to him, our conceptions do not come from external senses because the conceptions which I have of myself, of my thought, being, substance, action, identity, and the like, come from inner introspection, or reason (Hamlyn, 1967). No monad can be affected by anything external to it; but we nevertheless have knowledge of external things, because the mind is so constituted as to reflect ideas of external reality.

The British empiricists of the 17 th century were opposed to rationalism in the latter's views concerning the source of true knowledge. John Locke, for example, argued that there are no innate ideas; rather, the intellect is like "white paper" from inception (Essay Concerning Human Understanding, Book II; Chapt. 1, 2). There are only data of experience, which are either external (as in sensations), or internal (as in reflection, perception, belief, doubt and ideas which flow from the data). Ideas are whatever the mind attends to, or is aware of; and they are either simple or complex (Tipton, 1996; Stroll and Martinich, 2017). The former are passively received, individuated or immediate content of a perception, while the latter are combinations of the former and include abstract ideas, such as universals. George Berkeley's position is that whatever exists consists in an idea in the mind. For him, "To exist is to be perceived." (The Principles of Human Knowledge, 1710/2017:11). Physical things, such as stone, table, house, and people, are orderly collections of mind-dependent ideas. David Hume took it for granted that knowledge is limited to sense experience; more precisely, to perceptions whose contents are basically sense-data (A Treatise of Human Nature, Book I). Perceptions are subdivided into "impressions", which are vivid original perceptions, and "ideas", which are less lively copies of impressions (Jacobson, 1996:124). Without impressions, there can be no ideas, whether of things or of the world, as distinct from our impressions of them. That impressions are prior to ideas is clear from the simple fact that a man born blind has no idea of colours, having never had such impressions before. Any knowledge of something beyond our sense impressions is the consequence of speculative reasoning from immediate sense impressions to their supposed sources. Immanuel Kant notably distinguished between 'nuomena' and 'phenomena'-that is, things in themselves and things as perceived by the percipient. He posited that we can only know the latter, not the former (Allison, 1995:435).

\section{ILLUSION: INSTANCES AND CAUSES}

Illusion is, according to Smith (2002:23), "any perceptual situation in which a physical object is actually perceived, but in which that object perceptually appears other than it really is." Thus, 
despite the above submissions of the empiricists, there are instances of sensory perception which present distorted or false impressions to the perceiving subject. Under such circumstances, what is actually perceived fails to accurately represent the object stimulating the sense organs. Here, illusion is defined in terms of a perception that does not agree with the stimulus impinging on a sense organ because, taken by itself, the stimulus is often an ambiguous sign of what is present in the scene (Rock, 1977:784). If perception is considered to be the result of the principles of brain function, which are based on the sensory information available, it is plausible to suppose that these functions will not always lead to correct perceptions. Whenever they do not, we have illusions. As accounts of reality in science get ever more separated from appearances, to say that this separation is illusion would have the absurd implication that almost all perceptions are illusory. Thus, it seems better to view illusion as a systematic discrepancy between sensation and actual reality.

There are two kinds of illusion: those with a physical cause, and cognitive illusion, which are due to the misapplication of knowledge (Gregory, 1997:2). Although these two types have extremely different kinds of causes, they can produce some surprisingly similar phenomena such as distortions of length or curvature (Millar, 2015:610). Illusions due to the disturbance of light, between objects and the eyes, are different from illusions due to the disturbance of sensory signals of the eyes, though both are classifiable as physical. But they radically differ from cognitive illusions, which are due to (misapplied) knowledge employed by the brain to interpret or read sensory signals. These can be misleading in unusual conditions, but can be revealed by observation and experiment. Examples include seeing a grainy texture as wood, though it is a plastic imitation, or just a picture; a hollow mask, which is actually concave, is perceived as convex because faces are rarely hollow in reality and because the perceptual hypothesis of a face carries the not always true belief that faces are convex (Gregory, 1997:2). This is caused by clever lighting and rotation of the mask.

Philosophers also distinguish between illusions par excellence, and illusions due to relativity of perceptions and hallucinations (Hirst, 1967:131). The first class of illusions occurs in actual cases of illusion such as optical illusions; for example, the Muller-Lyer instance in which two lines of equal length appear unequal due to slight variation of features; mirages, mirror effects and magic tricks. The perception of motion introduces other illusory experiences, such as motion pictures at a cinema, where a rapid succession of slightly different still pictures gives the impression that persons in the pictures are actually moving. Also, the wheels of a moving coach, although moving forward, seem to move in the opposite direction.

On the other hand, illusions due to relativity of perception are largely due to the position, perspective or distance of the perceiving subject. For example, a round plate, when tilted, appears elliptical in shape; the same water may feel cold or warm to two different persons. Again, a pair of coloured spectacles turns one's visual field into the same colour; and, depending on what one has been eating, the same wine may taste sweet, bitter, or dry. The pitch of a car's horn changes as the car rushes past, though the same pitch is maintained in that duration; sometimes, watching a moving vehicle from inside another motionless vehicle creates the erroneous impression that one's own vehicle is moving when it is actually stationary. These are, however, not typical cases of illusion. In the case of hallucinations, some physical object is perceived when in fact neither it nor anything like it is present. Examples include dreams, phantoms, an amputated toe, which still seems to ache the amputee; a drunkard "sees" objects that are not there, and yet which are big like an elephant.

There are other cases of illusions which cannot be properly categorised. A finger placed in front of the perceiver gets doubled as she gazes beyond it (Pryor, 2002). Finally, a pen held between the index finger and the middle finger gives the impression of only one pen; but when the fingers are crossed, one has a feeling of holding two pens, instead of one (Kagan and Segal, 1992:146). Illusions can also result from physical laws, such as when a straight stick is immersed in water and it appears bent. They can also have psychological causes, such as the illusion of control, wherein a man feels good by believing that things are under his control when, in fact, they are not. Illusions can be passive and so, distinguishable from active illusions that are explained by the subject's expectant attention, distraction, or emotion (Siwek, 1967:368f.). In all these cases, one thing is common: there has been an error in perception; a distorted perception of an object, real or unreal. All cases of illusion are, therefore, akin to the circumstance 
of things not being what they seem to be.

A fundamental epistemological concern raised by philosophers hinges on sense perception and the fact of illusion. Such problems, as we shall see hereafter, center on the question of the extent to which perception can give us true and direct knowledge of the external world. Because errors of perception can arise from knowledge being inappropriate or being misapplied, some scholars, especially in Psychology, believe that illusions are very important towards the investigation of cognitive processes like vision (Gregory, 1997:1). So, they tend to uphold the controversial externalist position that prior knowledge makes a major contribution to human perception as in vision.

\section{THE SCEPTICAL ARGUMENT FROM ILLUSION}

The question naturally arises: If the senses are 1 so prone to deceive, as is clear from all the 2 . above instances of illusory perception, and given that knowledge, especially scientific knowledge, 3 . demands certainty and exactitude, to what extent can we legitimately lay claim to true knowledge of external reality, going strictly by the senses? How do we recognise the present without confusion 4 . from the past? In other words, how can we tell the difference between a situation in which there is illusion and one of veridical experience of objective reality? Even if there are cases when we clearly are not under illusion, the fact that 5 . there are cases pointing to the contrary seems to create a serious problem for the empiricist account of knowledge. The additional problem that we are even unaware of the fact when we 6 are truly deceived by the senses further diminishes our ability to make the distinction between illusion and reality. Dancy (1995:421) 7 . describes this phenomenon as a state in which: [G]enuine awareness of a world may be indistinguishable from one which is a mere appearance. [Thus,] one cannot tell from the phenomenology of one's awareness which it is an illusion or awareness of an external reality.

Take the case of dreams, which are a typical example of hallucination, for instance. Although some people claim to know when they are dreaming, there is very little doubt that most dream experiences, particularly if the sleep is deep enough, often portend no practical difference for the percipient from real life or wakefulness.

Russell (1912:5) and Ayer (1940:10) were leading contenders for the argument from illusion, while Austin (1962:7) was its renowned critic, although Austin is sometimes thought to have substantively misrepresented Ayer's brilliant skepticism in this regard. The main aim of the argument from illusion is to show that the senses are not reliable, and that perception is not correct and certain awareness of the real properties of material objects, but only that of appearances (Dancy, 1995:421; Akintona, 2015:75). Various conclusions can be drawn from this. The first is that for knowledge that is certain, we must rely not on the senses but on some other faculty, such as intellectual intuition (pace Descartes); another is that we must abandon common-sense realism (Hirst, 1967; Smith, 2002). Using the case of the stick submerged in water as illustration, the argument from illusion may be systematically outlined as follows (Pryor, 2002:par.10):

\section{The stick appears bent.}

So, there is some bent shape in my visual field, which I am aware of.

But the real stick I am looking at out there in the physical world is not actually bent. It is in fact straight. (And if I were hallucinating a bent stick, there would not be any real object I am seeing).

So the bent shape I am aware of cannot be identical to the real stick (due to this difference). The bent shape is not a physical object. It is something mental called my 'sense-datum' of the real stick.

In cases of illusion and so on, what we are directly aware of are not real physical objects, but only the sense-data or appearances those objects produce in us (such as an after-image).

From the inside, cases of veridical perception seem to be just like cases of illusion or hallucination.

Therefore, what we are directly aware of in cases of veridical perception must also be sense-data. If what we were directly aware of in one case were things in our mind, and in the other case, were physical objects in the external world, then we would have been able to notice there is some difference.

The first stage of this argument (premises 1-4 above) tries to show that in all cases of illusion, there are things called sensedata that really have the properties that external objects seem to us to have, and that are what we are directly aware of. The second stage (premises 5 to the conclusion) extends this result to cases of veridical perception as well. On this sense datum theory of perception, the question arises: "given that we are only acquainted with 
sense data in perception, how could perception justify beliefs about external objects?" (Speaks, 2004:5) So, if we believe in these sense-data, they will be things we can know about in every case of perception, regardless of how favourable the external conditions of perception are, or are known to be. This gives us the following summarised proposal:

If you perceive $x$ as $F$, and you have reason to believe that the perceptual conditions are currently 'normal' or favourable, and $\mathrm{x}$ is really $\mathrm{F}$, only then are you in a position to know that $\mathrm{x}$ is $\mathrm{F}$ (Pryor, 2002:par.10).

Here, a further problem arises concerning how you can ascertain that your perceptual conditions are currently normal. To say that you are certain because you perceived them to be normal would only beg the question. Based on this proposal, the skeptic concludes that we cannot know anything on the basis of perception, unless we have independent reasons (that is, independent of perception) for believing that out perceptual conditions are normal. Yet, how are we to know that, if not by perception?

Attempts to explain away illusions include the eye-movement theory based on the realisation that impression of length seems to be based upon scanning a figure by moving the eye from one end to another. If the eyes take a greater scanning movement, they tend to perceive that particular instance as longer or lengthier. An example is the Muller-Lyer illusion. But this explanation is faulted by the fact that even a split second view of these two figures produces the same impression. Another example is the Gestalt theory, which is based on the principle that particular impressions are largely determined by other features of the visual field, as well. For instance, when a gray colour is surrounded by black, in one case, and white, in another case, it seems much lighter in the first case, but much darker in the other; whereas it is the same gray. This theory has been criticised as being too general to explain the specific effects obtained in most cases of illusion, such as Herring's illusion, whereby two horizontal and perpendicular lines appear curved to an onlooker.

\section{CRITICAL IMPLICATIONS FOR SCIENCE AND EPISTEMOLOGY}

Confronted with this apparently water-tight argument, one might be tempted to conclude, or, at least accept, that the skeptic is right: that we really do not know the things we thought we knew. Yet the argument from illusion is dotted with some deep-seated problems, especially as considered from the point of view of science. For example, a straightforward observation that may be made here is that technology is simply the implementation of scientific commonsense. It is the (successful) application of scientific knowledge. Based on this simple observation, it can only be evident that the extremist claim of the skeptic that human knowledge is illusory contradicts commonsense by ignoring the innumerable cases in which knowledge has been successfully applied under purely natural circumstances in order to resolve long-standing problems of the human condition. To wit, the fact of technology is a simple, clear indication that humans are under no absolute illusion, even if the compelling philosophical argument with which to match the sophistry of the skeptic were lacking. Also, as Bruno (2012:44) noted, further proof that perception is not always illusory is "its adaptive function of providing us with a behaviorally useful representation of the external environment." The kind of organised societies in which humans live, and aspire to live, lends credence to the fact that we are not under illusion in any absolute sense. These examples are, in effect, why the argument from illusion failed to impress some inner-chamber epistemologists (Phillips, 2013:417).

To be adequately forceful against empiricism, the argument from illusion must include the claim, or at least the assumption, that humans are abjectly ignorant of being under illusion in every case of sensory perception. If it so much as concedes that there is such a thing as veridical perception, in virtue of which humans are sometimes free from illusion, then it would not be controversial at all. As such, its tour de force lies in the claim that there is no direct means of distinguishing between veridical and illusory perceptual experiences. Since the time of ancient Greek thinkers, questions of how genuine knowledge comes about in humans have been of deep interest in philosophy. Also, largely due to its empirical nature and its reliance on the a posteriori methods of inquiry, science is notable for its deeply entrenched concern with knowledge derived from experience, without which scientific inquiry would be inconceivable. Thus, the argument from illusion was of crucial interest to philosophers and scientists because it stood as a direct challenge to the image of science as the "paradigm of institutionalized rationality" (NewtonSmith, 2003:1). The skeptic position commits one to viewing the world as a place where no one can distinguish between hallucinatory states and 
actual states, thus rendering all scientific knowledge dubious, and making it most absurd that certain persons are categorised as 'schizophrenic' when, in fact, all humanity is guilty.

Albeit, the argument from illusion totally relies on the sense-datum theory, which equates illusions and objective reality and their perceptions to sense-data or mental objects (constructs), thereby suggesting that illusions are not different from veridical perceptions (Ayer, 1940:4). In this way, it subtly assumes that the sense-datum theory is true (Akintona, 2015:76). Unfortunately, this theory has been under intense controversy among frontline epistemologists from the onset, as a result of which it has been steadily modified. Thus, for obvious reasons, it has lost much of its earlier attraction and cogency in the course of the debate. First, sense-data seem to possess spatial properties, but their actual location is not obvious; and since they cannot be located in physical space, are they to be conceived as existing in a "mental space"? Second, since, according to the sense-datum theory, sense-data is to be equated to objective reality and an elephant is perceived to be very big and heavy, does that mean that the sensedatum of an elephant is also that big? Third, what is the relationship between these sense-data and the brain, which is the medium of their interpretation? Are they part of the brain, or produced by it? Does not this theory commit one to some kind of mind/body dualism? Again, how can my sense-datum be as big as an elephant if it is part of my brain or myself, none of which is as big as an elephant? Thus, in positing the idea of sense-data, the argument from illusion created bigger problems than it set out to solve.

When it comes to the process of human knowledge and the endeavour to know, illusions are an exception rather than the rule. Illusions are, as Bruno (2012:44) tactfully put it, "perceptual and stimulus inconsistency." In other words, they are problems; and, as do all problems, they arise only when there is discrepancy between expectation and actual state of affairs, for which solution can only be sought. Human knowledge proceeds normally as it should until a discrepancy arises to create stopgap. But the argument from illusion impresses one otherwise, making illusions the norm, rather than the exception to the rule. This conflation is, again, misleading and contrary to experience, because:

The world is not such a grotesque nightmare ... as a rule, things are what they look like, or otherwise expressed, their looks tell us what to do with them .... Why is it that our behaviour, directed as it is by objects in the behavioural environment, is, as a rule, also adapted to objects in the geographical environment? (Koffka, 1935:76; quoted in Bruno, 2012:58)

In fact, hallucinations generally occur in very special circumstances, when the victim is suffering from high fever, drunkenness, drugs, starvation, religious ecstasy, or downright madness. Even mescaline hallucinations do not always impair the mental powers of victims, who are, sometimes, able to recognise being under its influence. The skeptic argument assumes that things always appear other than they actually are; or that things can only be other than they look. But one may deny this assumption and, instead, simply insist that one is actually seeing a round plate that merely appears elliptical from one's present position. Treating appearance as reality as though the former were an individuated, ontological category is, as Austin (1962:6) argued, part of the causes of the confusion engendered by the skeptic challenge to the validity of human knowledge. Yet "appearance refers to how things are presented to the senses, not to some other object as distinct from the original object" (Gregory, 1997: 133).

In meeting the skeptic challenge, one may not only point to the comparative rarity of illusion, but also to the efficacy of the various tests that can be carried out to remove doubt. For instance, we can use one sense to complement another for better perceptive accuracy. A wax fruit that looks real can be revealed by the application of the senses of touch, taste, and smell. Measurement can settle any doubt on the real size, shape, or weight, of an object, just as memory and sight can show that a phantom limb does not exist. Proof for the relative reliability of perception can be aided by photographing; if it is doubted that an object appears in a certain way, we can take a photograph of it so that others can confirm that the picture copies the object, or something else. Quite fundamentally, attitudes and instructions on how to view illusions have been found to have positive effect on illusions, which have tended to decrease with practice at overcoming them. This is thought to be a function of repeated exposure, which in turn, may be the result of changing attitudes, or of physiological "fatigue" effects. The fact that there are illusions makes it clear that perception is not merely a matter of interpreting sensory information on the basis of knowledge already possessed; for illusions generally occur despite knowledge of the 
contrary. Although these approaches would greatly reduce illusion, the skeptic might insist that it is not absolutely certain. Yet it is both logically absurd and intuitively impossible that we suffer from hallucination all the time; for if no perception is certain, and there is no way of distinguishing illusion from veridical perception, then the world would be impossible to deal with intellectually. As Hirst (1967:132) suggested, to say that even well-tested perceptions are only probable is to collapse the distinction between certainty and probability.

The skeptic relies on a vague notion of certainty; there is no reason to suppose that ordinary perceptions are uncertain in the same way as future outcomes, or results, are uncertain (for instance, next year's weather, or a football tournament result). The fact that humans are aware of the possibility of illusion; the fact that there is something called illusion and, in fact, that we are having this debate on illusion, casts a huge shadow of doubt on the cogency of the argument from illusion. It means that, at least, we recognise that there is a problem (called illusion). Most importantly, it implies that this is not the way things always are in real life, since problems arise only if (and when) there is discrepancy, as was noted earlier. If all this is true, then, clearly, illusion cannot be the way things generally are in the world; and this is a major step away from abject ignorance of the possibility of illusion, on which the argument from illusion relies. With this knowledge, we are only poised to deal with the problem.

The argument from illusion tacitly assumes that human beings do not learn from experience, and, in fact, that they are hopelessly incapable of doing so. However, due to the awareness of the possibility of illusion based on past experience, humans are capable of suspending judgment until investigation is finalised. If one learns that one had really been under an illusion, why would one accept that situation and continue in error, fully aware of the delusion? To use the example of the stick partially submerged in water: why would one jettison the fact that the stick is actually not bent at all, and rather settle with the illusion that it is bent, just because it appears so while submerged in water? After all, one is amply capable of removing it from the water, in order to assure myself and others that it is, in fact, not bent at all, following which even the most naïve onlooker would agree that the bent appearance of the stick must have something to do with the water medium in which it is partly submerged. Thus, fortunately, humans are capable of learning about illusions and correcting them for better future perceptual experience. This is, in fact, human nature. Even when under illusion, humans are capable of eventually arriving at the veridical situation of outer reality and rebuilding their entire belief system based on the new eventuality. The enterprise of science has this as core objective: guiding human knowledge through trial and error and then retrial, in ways that are, at least, considerably objective by all reasonable standards.

Knowledge is procedural rather than automatic, contrary to the impression created by the skeptic, whose position, according to Smith (2002:25), is summarised in the following claim:

Since the wall is white, not yellow, but what we are immediately aware of is yellow, not white, what we are immediately aware of cannot be the wall. This third step is but an application of Leibniz's Law to illusory situations.

If you look at an object from a distance and perceive it as a yellow board at first, why would you simply settle for that initial impression, knowing (from experience) that error is always a possibility? Why would you stop there when there is freedom and possibility of moving closer and eventually discovering that you had actually been looking at a white wall, rather than some illusive yellow board? When we are not clear about a phenomenon unfolding before us, we naturally tend to move closer so as to get a clearer view and be sure of what is going on. Thus, illusion generally happens when we fail to take a closer look. This is how human knowledge develops in reality. But the skeptic would contrive things to seem that humans simply run with whatever impression their visual field throws at them at first glance. Human knowledge is gradual and procedural, not a one-fell-swoop phenomenon that requires no progress, or development.

There is such a thing as perspective, or point of view, from which individual and independent perceiving subjects can legitimately report what they perceive, even though perceptual error may be apparent. For example, two or three individuals may report different perceptual experiences from their diverse perspectives, all the while knowing that only one, or none, of these perfectly represents the perceived object. They all know that the object being viewed is actually white in colour, but due to the different light intensities, they perceive different colours from their respective vantage points. And when they trade positions, each reports exactly what the last person occupying 
the position reported. In this guise, each particular report can be both correct and incorrect at the same time; "correct" in the sense that they are right in reporting that the object-which is actually white in colour-appears yellow to them from a particular perspective, as anyone who assumes that particular position would also report the same perceptual content, under normal circumstances. But, again, their report is, at the same time, incorrect, due to the fact that it falls short of the actual state of the object being viewed, reporting it as yellow, though it is actually white. Yet no one is under any illusion about the actual colour under observation.

Whatever validity there is in the argument from illusion is seriously challenged by the successful application of human knowledge and logic, as well as the giant strides being recorded in different areas of human inquiry. In natural science, for example, no knowledge is worth the name unless it is subjected to critical analysis, tested over and over, and duly confirmed, before being accepted as basis for further inquiry. This means that there is no such thing as absolute knowledge in science; rather, current knowledge is always in a flux, as new insight and evidence come to light, thereby forcing us to modify, revise and update existing knowledge. If the insinuations of the argument from illusion were true, then even science itself would be a fruitless exertion. However, science has at least one merit: inherent determination to reduce illusion to the barest manageable minimum, so as to guide the intellect to the attainment of knowledge. Truly, there are many things we do not yet fully comprehend about reality. But the passing of each day marks some progress in that direction; and the little we do know makes sense and has, so far, enabled us to cope with the world around us, at least, as we have come to know it.

The argument from illusion is imbued with the fallacy of converse accident, the temptation to argue from a few instances of a given situation to the sweeping generalisation that all aspects of reality are in a certain way (Copi and Cohen, 1994:210f.; Odozor, $2015: 149$ ). If, as noted earlier, it is even conceivable that humans are capable of coming out of illusion, or of being under no illusion sometimes, then the argument from illusion is a clear case of moving from single instances (of illusion) to the universal declaration that all purported human knowledge is illusory; that is, arguing from the single, local instances of illusion to the ambitious, global conclusion that we are always under illusion. But "the fact that we can sometimes be wrong does not entail, but rather precludes, that we could always be wrong" (Schönbaumsfeld, 2017:5). Every sceptical argument of this nature proceeds from prima facie reasonable premises to an absurd conclusion that we do not know things we feel quite certain we do know. This shows that one of the premises on which the argument from illusion relies is false. It may, thus, be better to locate and reject that premise than to accept the absurd conclusion. In any case, the fact that an argument is valid does not suffice to establish the fact that it is sound. It only establishes a logical connection between the premises and the conclusion. Thus, the sceptical conclusion can be construed as reductio ad absurdum of its premises. In other words, it reduces its premises to absurdity in light of actual experience. But human intellectual history is itself another ample demonstration of how untenable it is to suppose that knowledge of the physical world is absolutely impossible.

It is also clear that the mental processes responsible for perception are not themselves conscious or directly observable. If they were, we would, as Rock (1977:786) hinted, have been able to explain our illusory experiences. Strictly speaking, though, it is not the senses that cause illusion as such. Whatever may be the cause of illusion, it need not be associated with sensation itself. Illusions are intricately connected with what the brain makes of the sensory stimuli pouring into the consciousness from the environment (Omoregbe, 1998:84f.). The sense organs intercept and present external impressions in much the same way as would any recording equipment in a physical laboratory. Error occurs when these sense-data are combined in perception through "the influences of ... laws of attention, past experiences and habitual ways of reacting" (Siwek, 1967:369).

\section{CONCLUSION}

This paper evaluated the problem of illusion from the perspective of its implications for science and epistemology. It found that the argument from illusion, though it has lost much of its force, derives merit from forcing us to rethink the claims of science to indubitable knowledge and certainty about reality. Exploring the nature of illusion, the paper also found that the argument from illusion is mistaken in treating perceptual illusion as the norm rather than an exception to the rule, and viewing human knowing process not as a 
gradual, piece-meal phenomenon, but as an instant, magical realisation, or awakening of human consciousness. Arguments having the same nature with the argument from illusion abound in different areas of philosophy, even from inception (Dancy, 1995:421). But such sceptical arguments typically proffer no solution to philosophical problems; rather, they are satisfied with merely leaving the human intellect miserable, in a dark, pessimistic way. Here, the traditional argument usually adduced to defeat skepticism also applies: if the argument from illusion is true, then we are under illusion that it is true, as we have no independent way of breaking free of this illusion and knowing that what the skeptic is saying is true. As French and Walters (2015:16) summarily noted: "There is, as yet, no persuasive argument from illusion, or from the considerations that drive it, against the common sense picture of veridical perception, even granting the Phenomenal Principle." To this extent, it is evident that the argument from illusion holds no promise even for the skeptic, and that we can attain knowledge of reality, albeit, procedurally.

\section{REFERENCES}

Akintona, E.O., 2015. "The Argument from Illusion and the Challenges of Human Perceptual Experience." In Ali, S.A. and Akintona, E.O. (Eds.). Readings in Philosophy: Problems and Issues. Lagos: Triumph Publishers. 75-85.

Allison, H.E., 1995. "Kant, Immanuel." In Honderich, T. (Ed). The Oxford Companion to Philosophy. New York: Oxford University Press. 435-438.

Aquinas, T., 1981. Summa Theologiae. Vol.1. Westminster: Christian Classics.

Aristotle., 1907. De Anima. Transl. Hicks, R. D. Cambridge: Cambridge University Press.

Austin, J. L., 1962. Sense and Sensibilia. Oxford: Oxford University Press.

Ayer, A.J., 1940. The Foundations of Empirical Knowledge. London: Macmillan.

Berkeley, G., 1710/2017. The Principles of Human Knowledge. Jonathan Bennett. Retrieved 22 October, 2018: https://www.earlymoderntexts.com/asset s/pdfs/berkeley1710.pdf

Bruno, N., 2012. "Illusions That We Should Have But Don't." In Calabi, C. (Ed.). Perceptual Illusions: Philosophical and Psychological Essays, Palgrave Macmillan. 44-58.

Copi, I.M. and Cohen, C., 1994. Introduction to Logic. 9th ed. New Jersey: Prentice-Hall.

Crane, T., and French, C., 2016, "The Problem of Perception." In Zalta, E.N. (Ed.). The

Stanford Encyclopedia of Philosophy. Retrieved August 19, 2018, from: http://plato.stanford.edu/archives/spr201 6/entries/perception-problem/

Dancy, J., 1995. "Arguments from Illusion." Philosophical Quarterly. 45(181):421438.

De Raeymaker, L., 1962. Introduction to Philosophy. Transl. McNeill, H.; New York: Wagner.

Descartes, R., 1997. "Meditations on First Philosophy." In Chávez-Arvizo, E. (Ed.). Descartes: Key Philosophical Writings. Transl. Haldane, E.S. and Ross, G.R.T. London: Wordsworth. 123-190.

French, C. and Walters, L., 2015. "The Invalidity of the Argument from Illusion." Retrieved August 22, 2018, from: http://craigafrench.github.io/assets/lllusio n.pdf

Gregory, R.L., 1997. Knowledge in Perception and Illusion. London: The Royal Society.

Hamlyn, D.W., 1967. "Epistemology, History of." In Edwards, P. (Ed.). The Encyclopedia of Philosophy. Vol.3. New York: Macmillan. 3-38.

Hirst, R.J., 1967. "Illusions." In Edwards, P. (Ed.). The Encyclopedia of Philosophy. Vol.4. New York: Macmillan. 130-133.

Hume, D., 1740/2003. A Treatise of Human Nature. New York: Dover.

Jacobson, A.J., 1996. "David Hume on Human Understanding." In Brown, S. (Ed.). Routledge History of Philosophy. Vol.5. London: Routledge. 123-146. 
Kagan, J. and Segal, J., 1992. Psychology: An Introduction. 7th ed. London: Harcourt, Brace and Jovanovich.

Koffka, K., 1935. Principles of Gestalt Psychology. Oxford, England: Harcourt, Brace.

Locke, J., 1690/2017 Essay Concerning Human Understanding. Jonathan Bennett. Retrieved 21 October, 2018: https://www.earlymoderntexts.com/asset s/pdfs/locke1690book2.pdf

Millar, B., 2015. "Naïve Realism and Illusion." Ergo: An Open Access Journal of Philosophy. 2(24): 607- 625. http://dx.doi.org/10.3998/ergo.12405314. 0002.024

Newton-Smith, W.H., 2003. The Rationality of Science. London: Taylor and Francis.

Odozor, U., 2015. "Basics of Logic." Studies in Arts and Social Sciences. Abeokuta: Jacob and Lydia Publishers. 86-159.

Omoregbe., 1998. Epistemology: A Systematic and Historical Study. Lagos: Joja.

Phillips, I., 2013. "Afterimages and Sensation." Philosophy and Phenomenological Research. 87(2): 417-453. London: Wiley.

Plato, 1883. The Theaetetus. 2nd Edition. Transl. Campbell, L. London: Clarendon.

Pryor, J., 2002. "Theory of Knowledge: Perception and Sense-Data." Unpublished Tutorial. Retrieved July 26, 2003, from: http://www.princeton.edu/ jimprior/cours es/epist/notes/sensedata.html

Rock, I., $1977 . \quad$ "Illusion." Encyclopedia Americana. International Edition. New York: Americana Corporation. 784-786.

Russell, B., 1912. The Problems of Philosophy. London: Williams \& Norgate.

Schönbaumsfeld, G., 2017. "Beliefs-in-a-Vat." Proceedings of the Aristotelian Society. 117(2). 4-21.

Siwek, P., 1967. "Illusion." New Catholic Encyclopedia. Vol.7. New York: McGrawHill.

Smith, A. D., 2002. The Problem of Perception, Cambridge: Harvard University Press.

Speaks, J., 2004. "Ayer on the Argument from Illusion." Unpublished Online Tutorial for Philosophy 370. Retrieved August 27, 2018, from: https://www3.nd.edu/ jspeaks/courses/m cgill/370/winter2004/ayer-argumentillusion.pdf

Stroll, A. and Martinich, A.P., 2017. "Epistemology." Online Encyclopædia Britannica. Encyclopædia Britannica, Inc. Retrieved August 27, 2018, from: https://www.britannica.com/topic/epistem ology\#ref849217

Stumpf, S.E., 1994. Philosophy: History and Problems. 5th Ed. New York: McGrawHill.

Tipton, I., 1996. "Locke: Knowledge and Its Limits." In Brown, S. (Ed.). Routledge History of Philosophy. Vol.5. London: Taylor and Francis. 56-77. 